\title{
Monitoring Circulation During Transition in Extreme Low Gestational Age Newborns: What's on the Horizon?
}

\author{
David Van Laere ${ }^{1,2 *}$, Michiel Voeten ${ }^{1,2}$, John M. O' Toole ${ }^{3}$ and Eugene Dempsey ${ }^{3}$ \\ ${ }^{1}$ Department of Neonatal Intensive Care, Antwerp University Hospital, Antwerp, Belgium, ${ }^{2}$ Laboratory of Experimental \\ Medicine and Pediatrics, Faculty of Medicine and Health Sciences, University of Antwerp, Antwerp, Belgium, ${ }^{3}$ Irish Centre \\ for Fetal and Neonatal Translational Research, University College Cork, Cork, Ireland
}

Echocardiography and near-infrared spectroscopy have significantly changed our view on hemodynamic transition of the extreme preterm infant. Instead of focusing on maintaining an arbitrary target value of blood pressure, we aim for circulatory well-being by a comprehensive holistic assessment of markers of cardiovascular instability. Most of these clinical and biochemical indices are influenced by transition itself and remain poor discriminators to identify patients with a potential need for therapeutic intervention. At

OPEN ACCESS

Edited by:

Yogen Singh, Cambridge University Hospitals NHS Foundation Trust, United Kingdom

Reviewed by: María Carmen Bravo, Hospital Universitario La Paz, Spain Shazia Bhombal, Stanford University, United States Fernando Cabañas, Hospital Universitario La Paz, Spain

*Correspondence: David Van Laere david.vanlaere@uza.be

Specialty section: This article was submitted to Neonatology, a section of the journal Frontiers in Pediatrics

Received: 19 January 2018 Accepted: 12 March 2018 Published: 26 March 2018

Citation:

Van Laere D, Voeten M, O' Toole JM and Dempsey E (2018) Monitoring

Circulation During Transition in

Extreme Low Gestational Age Newborns: What's on the Horizon?

Front. Pediatr. 6:74. doi: 10.3389/fped.2018.00074 the same time, the evolution in data capturing and storage has led to a change in our approach to monitor vital parameters. Continuous trend monitoring has become more and more relevant. By using signal extraction methods, changes in trends over time can be quantified. In this review, we will discuss the impact of these innovations on the current monitoring practices and explore some of the potential benefits these techniques may have in improving real-time detection of extreme low birth weight infants at risk for morbidity related to impaired hemodynamic transition.

Keywords: hemodynamic, circulation, preterm, signal analysis, monitoring

\section{INTRODUCTION}

Transition from the fetal to the neonatal circulation is a complex and challenging process. What is considered as a small step for a healthy term infant, is a giant leap for a vulnerable preterm neonate. An increased understanding of the (patho-)physiology of hemodynamic transition combined with the digital revolution and increased monitoring storage capacity has opened the gate toward a more individualized approach. As current literature lacks robust evidence on treatment thresholds, an in-depth knowledge of the transitional physiology with a specific focus on the vulnerability of the preterm cardiovascular system is the cornerstone to guide these infants through their hemodynamic journey in the first days of life.

\section{THE PHYSIOLOGY OF TRANSITIONAL HEMODYNAMIC ADAPTATION}

The fetal cardiovascular system has distinct morphologic and functional features that are different compared to the neonatal adapted circulation. The fetal myocardium consists of developing cardiac

Abbreviations: ELGANs, extreme low gestational age newborns; NICOM, non-invasive cardiac output monitor; NIRS, nearinfrared spectroscopy; PI, perfusion index; PVR, pulmonary vascular resistance; SVC, superior vena cave. 
myocytes with an immature cell structure $(1,2)$. In utero, the right ventricle is the dominant chamber and both ventricles contribute to systemic blood flow to ensure adequate tissue oxygenation in a low oxygen tension environment. Both pulmonary and systemic circulation work in parallel through the presence of intra- and extra-cardiac shunts (foramen ovale, patent ductus arteriosus). As oxygen is delivered through the placenta, blood is diverted away from the pulmonary circulation by maintaining a high pulmonary vascular resistance (PVR). The placenta functions as a low resistance system making afterload suitable for the developing heart.

At birth, the partial pressure of oxygen rapidly rises in response to lung aeration causing a drop in PVR and a redirection of the right ventricular output toward the pulmonary circulation (3). The loss of the placenta leads to a sudden change in loading conditions of the preterm myocardium as the placenta functions as a low resistance system in utero and holds a substantial part of the blood volume (4). On the other hand, afterload increases as clamping of the cord leads to a surge of catecholamines (5) and other vasoconstrictor substances resulting in a rise in systemic vascular resistance. Figure 1 gives an overview of the hemodynamic changes during transition from intra-uterine to extra-uterine life.

\section{THE PATHOPHYSIOLOGY RELATED TO PREMATURITY}

As the myocardium is in an embryological stage of development, the preterm infant is at risk of hemodynamic compromise. Compared to healthy term newborns, systolic and diastolic performance of the myocardium seems to be impaired (6). Changes in loading condition, as is the case during the transitional period, might not be well tolerated by the preterm heart (7). The difference in cord clamping time and increased risk of prolonged exposure to fetal shunts may lead to a variable degree of volume loading. The relatively high resting heartbeat, the variable ontogenic expression of adrenergic receptors and the immaturity of the hypothalamic-pituitary axis limit the ability of the preterm heart to increase contractility $(8,9)$. The context of prematurity (inflammation, sepsis) itself and the level of intensive

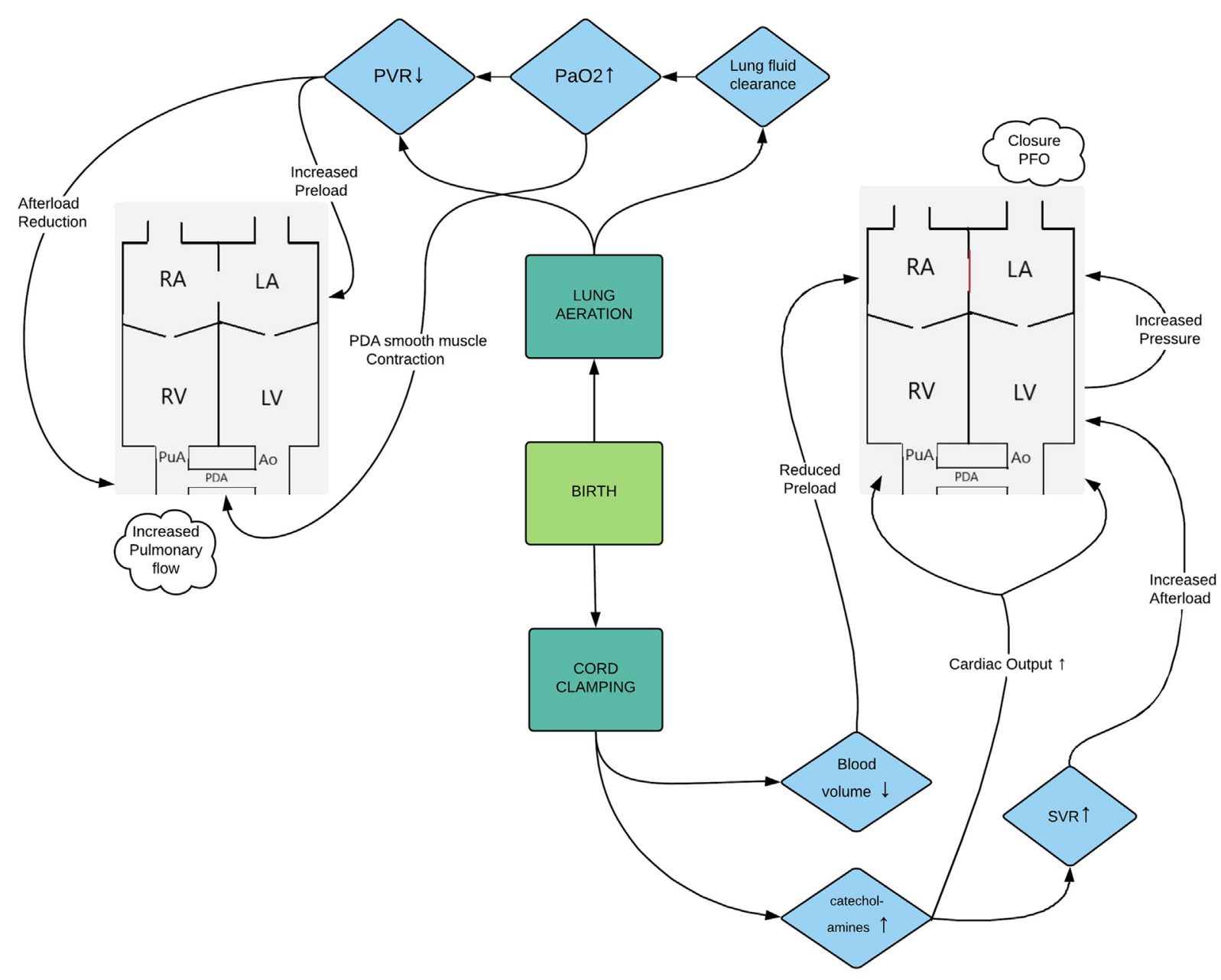

FIGURE 1 | Flowchart representing the hemodynamic changes during transition from intra-uterine to extra-uterine life. Abbreviations: Ao, aorta; LA, left atrium; LV, left ventricle; $\mathrm{PaO}_{2}$, partial arterial pressure of oxygen; PDA, patent ductus arteriosus; PFO, patent foramen ovale; PVR, pulmonary vascular resistance; PuA, pulmonary artery; RA, right atrium; RV, right ventricle; SVR, systemic vascular resistance. 
care treatment given at birth (ventilation, etc.) may also have an important impact on the cardiovascular response $(10,11)$.

To ensure normal cellular function, oxygen delivery must meet oxygen demand. This can only occur when oxygen content of the blood is ensured, and cardiac output and perfusion pressure are maintained. The most important clinical organ for impaired cardiovascular adaptation is the vulnerable preterm brain. Although multifactorial, studies with echocardiography have shown that transient reduced systemic blood flow plays a role in the pathophysiology of intraventricular hemorrhage $(9,12-14)$.

\section{A PRESSURE DRIVEN APPROACH}

Historically, a stringent approach based on mean arterial blood pressure was used to assess cardiovascular well-being during transition. This parameter is readily available and can be monitored continuously if an indwelling catheter is present. Although hypotension during the transitional period is associated with short-term adverse outcome (15), there is currently no evidence that treatment of low blood pressure improves outcome $(16,17)$. This might be related to an oversimplified approach in a complex clinical situation. The current thresholds for low blood pressure in neonates are statistically derived values based on studies done more than 20 years ago (18). The current cutoff values are the lowest centiles for blood pressure for a given gestational age, but they lack a physiological substrate at which disease occurs. Additionally, by using mean blood pressure, valuable information on the components of blood pressure is lost. Moreover, blood pressure is the dependent product of two independent variables: cardiac output and vascular resistance. During transition the correlation between systemic blood flow and blood pressure is weak (19). As such, the current cutoff values for hypotension have low sensitivity for detecting impaired cardiac output.

Recently a more pragmatic approach toward low blood pressure has found its way in many units. This consists of permissive hypotension if other hemodynamic parameters (heart rate, diuresis, lactate levels) are indicative of a state of cardiovascular well-being.

Randomized controlled trials are currently investigating whether a more stringent approach toward keeping blood pressure above a certain threshold is beneficial compared to an attitude of watchful waiting $(15,20)$.

\section{A COMPREHENSIVE NEONATAL HEMODYNAMIC MONITORING MODEL}

An idealistic hemodynamic monitoring model that allows for an individual assessment of changes in the circulation would consist of real-time assessment of myocardial function and stroke volume on the one hand and information on peripheral and/or end-organ perfusion on the other hand. Over recent years new monitoring modalities have found their way to clinical practice $(21,22)$ making it possible to receive additional information on end-organ perfusion in a continuous and non-invasive manner. Increased digital storage capacity has made it possible to visualize trends of vital parameters over time, shifting the focus away from a single "golden bullet" cutoff value at which disease occurs in a group of patients. With advancing computing capacity and improved extraction methods it has become possible to decompose monitoring signals and to quantify their different characteristics. Interaction between different monitoring signals can be interrogated. Signal analysis may have the potential to detect patterns in vital parameters that are predictive of a potential pathologic state.

We propose a hemodynamic monitoring approach that would include information on cardiac output by a non-invasive cardiac output monitor (NICOM) and point of care ultrasound combined with additional information of "classical" vital parameters and real-time information on cerebral and peripheral perfusion by near-infrared spectroscopy (NIRS) and plethysmographic Perfusion index (PI) monitoring, respectively (Figure S1 in Supplementary Material). As point of care ultrasound is beyond the scope of this review, we will provide an overview of the literature regarding validation and evidence associated with outcome of the abovementioned monitoring techniques in the preterm population. In addition, we will discuss the potential implications in clinical care of signal analysis of these continuously monitored parameters.

\section{Non-Invasive Cardiac Output Monitor}

Determination of blood flow through invasive techniques is an integral part of advanced hemodynamic monitoring in adult intensive care and perioperative medicine (23). NICOM is an emerging tool that allows for a continuous assessment of cardiac output. Currently available commercial monitors are based on bioimpedance (electrical cardiometry) or bioreactance technology. Cardiac output is derived by changes in either thoracic impedance or induced phase shift of an electrical current by pulsatile changes in blood volume (24). Validation studies in a preterm population have been performed. Left and right ventricular output measured by electrical cardiometry correlated significantly with echocardiographic measurements (25). There was no significant correlation with superior vena cava (SVC) flow. The limits of agreement were wide and decreased in the presence of high frequency ventilation and low output states, making the technique only feasible for trend monitoring. Another study of paired measurements performed in patients with a hemodynamically significant PDA showed similar findings (26). Reference normograms based on gestational age and birth weight were also recently published (27).

Non-invasive cardiac output monitor measurements of cardiac output based on bioreactance correlated well with left ventricular output on echocardiography in a study performed in term neonates (22). Readings of cardiac output, however, tended to under-read echo measurements. In a study performing paired measurements of bioreactance NICOM and echocardiography in preterm patients undergoing ligation showed that NICOM output measurements correlated well with stroke volume though there was a consistent underestimation with wide limits of agreement.

At present, no studies have been performed linking NICOM measurements with (adverse) outcome of prematurity. 


\section{Peripheral Perfusion Monitoring: PI}

Perfusion index is derived from the plethysmographic signal of a pulse oximeter. It is readily available on most monitoring systems in the NICU. The numerical value represents the ratio of light absorbed by pulsatile and non-pulsatile absorbers (28). As nonpulsatile absorbers are constant, the PI value is mainly influenced by arterial perfusion. Interestingly point measurements of PI during echocardiography correlated well with SVC flow in a study performed in preterm patients born before a gestational age of 32 weeks (29). A cutoff value of 0.44 had a negative predictive value of $98.6 \%$ for detecting low SVC flow during the first $72 \mathrm{~h}$ of life. Longitudinal reference values for PI during the first $72 \mathrm{~h}$ in patients born below a gestational age of 32 weeks have been published (30). The authors also presented the relationship of PI with clinical variables. PI was positively related with gestational age and negatively with mean arterial blood pressure and treatment with dopamine.

A recent study demonstrated that preductal PI and mean $\Delta \mathrm{PI}$ of pre- and postductal measurements $4 \mathrm{~h}$ prior to echocardiography were able to identify preterm infants with a patent ductus arteriosus (31). PI values have been linked with outcome in both term and preterm infants $(32,33)$.

In a study using signal analysis extraction methods, the PI signal was separated into a low frequency (trend) component and a high frequency (detrend) component (34). Mean and $\mathrm{SD}$ were used as quantitative features to assess differences in temporal evolution of the components between patients with acquired brain injury or early mortality and patients with normal short-term outcome. Interestingly, patients with adverse outcome had significantly overall lower trend values for the first $24 \mathrm{~h}$ and decreased detrend variability from $12 \mathrm{~h}$ onward compared to patients with normal outcome (Figure 2). These effects remained

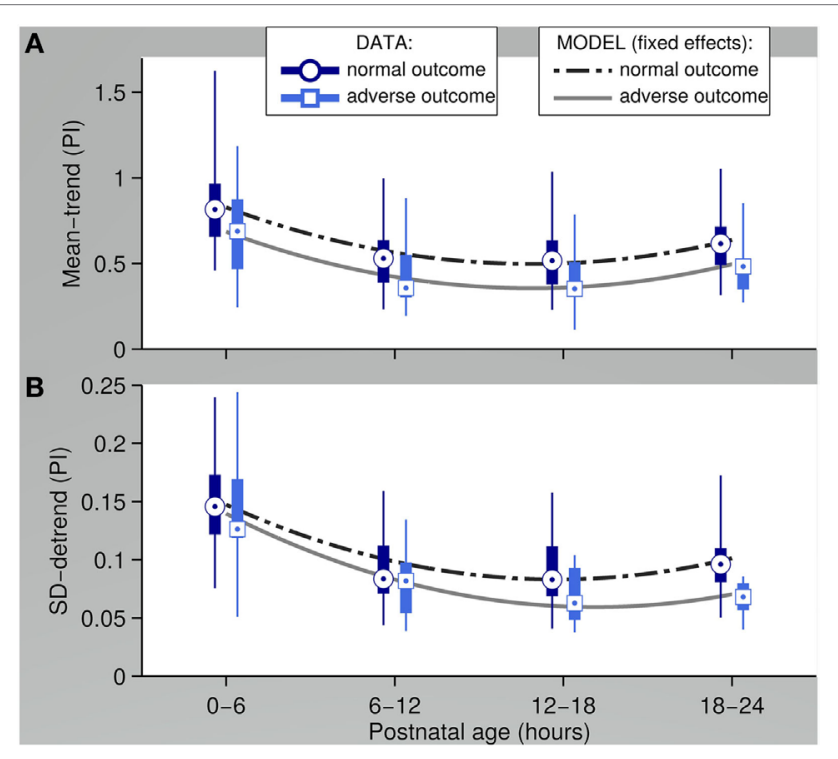

FIGURE 2 | Perfusion Index (PI) features assessed over a 6-h interval with fixed-effects (outcome group) from the mixed effects model in a study performed in extreme low gestational newborns. Adverse outcome was defined as early mortality or acquired brain injury (A) mean of the PI trend (B) SD of the PI detrend [data adapted from Van Laere et al. (34)]. significant when controlling for confounders such as gestational age and inotropic drug therapy. This study clearly shows that analyzing trend signals can identify subtle and clinically undetected changes in peripheral perfusion. The question remains if early identification and intervention can improve outcome.

\section{Cerebral Oximetry Monitoring: NIRS Monitoring}

Near infrared spectroscopy technique is based on different wavelength absorption of near infrared light between oxygenated and deoxygenated hemoglobin. These differences are detected by a sensor and subsequently used to calculate the concentration of both types of hemoglobin. RcSO2 or Tissue oxygenation index represents the ratio of oxygenated to deoxygenated hemoglobin (35). As such, it represents a mixed saturation largely determined by the venous component. Different commercial devices are available and the technique is well validated in infants (36). Reference values based on large observational study in preterm infants born before 32 weeks of gestation have been published (37). RcSO2 values generally increase after birth and normal values range between 55 and $85 \%$ depending on gestational age. Small neonatal sensors have been developed and are now in use. Understanding the device and its values is essential as neonatal sensors generally overestimate values compared to adult sensors $(38,39)$.

Acquiring real-time information on cerebral oxygenation can be valuable for managing cardiorespiratory support during transition. While many extreme preterm infants are still ventilated, arterial carbon dioxide pressure can affect cerebral blood flow, where hypocapnia induces cerebral arterial vasoconstriction and hypercapnia induces vasodilation. A trial that randomized patients to visible reading of regional saturation with adherent treatment guidelines versus a control group blinded to these measurements showed a significant reduction in the burden of cerebral hypoxia and hyperoxia (40). The trial was not powered to show differences in clinical outcome. Interestingly a post hoc analysis showed an association with lower early burden of hypoxia and severe brain injury of prematurity (41). More recently a feature set of the RcSO2 signal was developed for the purpose of detecting brain injury. Cross validation was performed in a cohort of infants $<32$ weeks of gestation. Although some features were significantly correlated with brain injury, sensitivity and specificity were moderate. Nevertheless, the quantitative analysis of the rcSO2 signal might contribute to early identification of infants at risk (42).

While continuous cerebral oxygenation monitoring can assess the real-time effect of interventions on brain perfusion, the most intriguing innovation comes from the ability to assess whether changes in the invasive blood pressure signal correlate with similar changes in the NIRS signal. This parameter can then be used as a surrogate measurement for cerebral autoregulation. The debate is still ongoing on whether cerebrovascular autoregulation is developmentally and postnatally regulated and how illness severity and concomitant treatment interact with it. Different techniques have been developed to quantify cerebral autoregulation. In essence, the relationship between both signals can be assessed in the time or frequency domain. Another technique suggested an approach using moving correlation between heart rate and NIRS derived variables, making it feasible for patients 
without an indwelling arterial line (43). A recent extensive review gives an in-depth overview on the current literature on this topic (44). Several studies with different techniques found a significant association with increased markers of impaired autoregulation and acquired brain injury of prematurity (43, 45-48). Providing real-time quantitative information on cerebral autoregulation could potentially imply that the clinician becomes aware of an individual safe range of blood pressure. At present, upper and lower thresholds of arterial blood pressure at which cerebral blood flow becomes pressure passive remain largely unknown due to a lack of consensus on the most robust methodology to assess cerebrovascular autoregulation and which outcome to measure.

\section{FUTURE PERSPECTIVES: TOWARD AN INDIVIDUALIZED APPROACH}

In the last decade, non-invasive monitoring tools have been developed and some of them already found their way to the bedside. Improved storage and computing capacity has made trend monitoring more feasible and attractive. Combining multiple parameters and quantifying signal characteristics make it possible to detect or predict disease in a subclinical phase. Monitoring heart rate characteristics for early detection of sepsis has shown to be associated with a reduction of septicemia related mortality (49). Technologies for automated seizure detection are currently being evaluated for additive diagnostic accuracy at the bedside (50).

At present, there is paucity of evidence on how treatment adherent to new parameters and innovative techniques can improve clinical outcomes in the preterm population during transition. Nevertheless, technological advancement has provided more insight in transitional physiology and the challenges for each individual preterm infant. The next step will be to incorporate real-time bedside signal processing monitors into

\section{REFERENCES}

1. Smolich JJ. Ultrastructural and functional features of the developing mammalian heart: a brief overview. Reprod Fertil Dev (1995) 7(3):451-61. doi:10.1071/ RD9950451

2. Samsa LA, Yang B, Liu J. Embryonic cardiac chamber maturation: trabeculation, conduction, and cardiomyocyte proliferation. Am J Med Genet C Semin Med Genet (2013) 163c(3):157-68. doi:10.1002/ajmg.c.31366

3. El-Khuffash A, McNamara PJ. Hemodynamic assessment and monitoring of premature infants. Clin Perinatol (2017) 44(2):377-93. doi:10.1016/j.clp. 2017.02.001

4. Siauve N, Chalouhi GE, Deloison B, Alison M, Clement O, Ville Y, et al. Functional imaging of the human placenta with magnetic resonance. Am J Obstet Gynecol (2015) 213(4 Suppl):S103-14. doi:10.1016/j.ajog.2015. 06.045

5. Habib DM, Padbury JF, Martinez AM, Chappell BA, Thio SL, Burnell EE. Neonatal adaptation: cardiac adrenergic effector mechanisms after birth in newborn sheep. Pediatr Res (1991) 29(1):98-103. doi:10.1203/00006450199101000-00019

6. Ciccone MM, Scicchitano P, Zito A, Gesualdo M, Sassara M, Calderoni G, et al. Different functional cardiac characteristics observed in term/preterm neonates by echocardiography and tissue Doppler imaging. Early Hum Dev (2011) 87(8):555-8. doi:10.1016/j.earlhumdev.2011.04.012

7. Lee A, Nestaas E, Liestol K, Brunvand L, Lindemann R, Fugelseth D. Tissue Doppler imaging in very preterm infants during the first $24 \mathrm{~h}$ of life: an observational study. Arch Dis Child Fetal Neonatal Ed (2014) 99(1):F64-9. doi:10.1136/ archdischild-2013-304197 clinical trials. As we are slowly but surely moving away from the era of pragmatic cutoff values for generalized treatment, a new individualized approach to treatment will pose a big challenge to the evidence-based neonatal community. Large collaborative networks on continuous data with input from biomedical engineers and computer scientist are the way forward to overcome these issues. We are hopeful that the next phase will be to feed monitoring algorithms with proven clinical usefulness into a cognitive computing model to develop a predictive monitoring system.

\section{AUTHOR CONTRIBUTIONS}

DL conceptualized this review and wrote the first draft and revised the manuscript for submission. All the other authors critically reviewed the manuscript. All authors approved the final manuscript as submitted and agreed to be accountable for all the aspects of the work.

\section{FUNDING}

DL received a grant by the European Union (FP7/2007-20013 under agreement 260777 the HIP trial). ED is supported by the Science Foundation Ireland (Research award INFANT - 12/ RC/2272) and by the European Union (FP7/2007-20013 under agreement 260777 the HIP trial). JO is supported by the Irish Science Foundation (15/SIRG/3580).

\section{SUPPLEMENTARY MATERIAL}

The Supplementary Material for this article can be found online at https://www.frontiersin.org/articles/10.3389/fped.2018.00074/ full\#supplementary-material.

FIGURE S1 | Photo of manikin representing a hemodynamic monitoring model in an extreme preterm infant.

8. Kojima M, Ishima T, Taniguchi N, Kimura K, Sada H, Sperelakis N. Developmental changes in beta-adrenoceptors, muscarinic cholinoceptors and $\mathrm{Ca}^{2+}$ channels in rat ventricular muscles. Br JPharmacol (1990) 99(2):334-9. doi:10.1111/j.1476-5381.1990.tb14704.x

9. Noori S, McCoy M, Anderson MP, Ramji F, Seri I. Changes in cardiac function and cerebral blood flow in relation to peri/intraventricular hemorrhage in extremely preterm infants. J Pediatr (2014) 164(2):264-70.e1-3. doi:10.1016/j. jpeds.2013.09.045

10. de Waal KA, Evans N, Osborn DA, Kluckow M. Cardiorespiratory effects of changes in end expiratory pressure in ventilated newborns. Arch Dis Child Fetal Neonatal Ed (2007) 92(6):F444-8. doi:10.1136/adc.2006.103929

11. Seehase M, Gantert M, Ladenburger A, Garnier Y, Kunzmann S, Thomas W, et al. Myocardial response in preterm fetal sheep exposed to systemic endotoxinaemia. Pediatr Res (2011) 70(3):242-6. doi:10.1203/PDR.0b013e318225fbcb

12. Miletin J, Dempsey EM. Low superior vena cava flow on day 1 and adverse outcome in the very low birthweight infant. Arch Dis Child Fetal Neonatal Ed (2008) 93(5):F368-71. doi:10.1136/adc.2007.129304

13. Noori S, Seri I. Hemodynamic antecedents of peri/intraventricular hemorrhage in very preterm neonates. Semin Fetal Neonatal Med (2015) 20(4):232-7. doi:10.1016/j.siny.2015.02.004

14. Osborn DA, Evans N, Kluckow M. Hemodynamic and antecedent risk factors of early and late periventricular/intraventricular hemorrhage in premature infants. Pediatrics (2003) 112(1 Pt 1):33-9. doi:10.1542/peds.112.1.33

15. Faust K, Hartel C, Preuss M, Rabe H, Roll C, Emeis M, et al. Short-term outcome of very-low-birthweight infants with arterial hypotension in the first $24 \mathrm{~h}$ of life. Arch Dis Child Fetal Neonatal Ed (2015) 100(5):F388-92. doi:10.1136/ archdischild-2014-306483 
16. Batton B, Li L, Newman NS, Das A, Watterberg KL, Yoder BA, et al. Use of antihypotensive therapies in extremely preterm infants. Pediatrics (2013) 131(6):e1865-73. doi:10.1542/peds.2012-2779

17. Alderliesten T, Lemmers PM, van Haastert IC, de Vries LS, Bonestroo HJ, Baerts W, et al. Hypotension in preterm neonates: low blood pressure alone does not affect neurodevelopmental outcome. J Pediatr (2014) 164(5):986-91. doi:10.1016/j.jpeds.2013.12.042

18. Zubrow AB, Hulman S, Kushner H, Falkner B. Determinants of blood pressure in infants admitted to neonatal intensive care units: a prospective multicenter study. Philadelphia neonatal blood pressure study group. J Perinatol (1995) 15(6):470-9.

19. Kluckow M, Evans N. Relationship between blood pressure and cardiac output in preterm infants requiring mechanical ventilation. J Pediatr (1996) 129(4):506-12. doi:10.1016/S0022-3476(96)70114-2

20. Dempsey EM, Barrington KJ, Marlow N, O’Donnell CP, Miletin J, Naulaers G, etal.Management of hypotensionin preterminfants(theHIPtrial): arandomised controlled trial of hypotension management in extremely low gestational age newborns. Neonatology (2014) 105(4):275-81. doi:10.1159/000357553

21. Korcek P, Stranak Z, Sirc J, Naulaers G. The role of near-infrared spectroscopy monitoring in preterm infants. J Perinatol (2017) 37(10):1070-7. doi:10.1038/ jp. 2017.60

22. Weisz DE, Jain A, McNamara PJ, EL-Khuffash A. Non-invasive cardiac output monitoring in neonates using bioreactance: a comparison with echocardiography. Neonatology (2012) 102(1):61-7. doi:10.1159/000337295

23. Saugel B, Reese PC, Wagner JY, Buerke M, Huber W, Kluge S, et al. Advanced hemodynamic monitoring in intensive care medicine: a German webbased survey study. Med Klin Intensivmed Notfmed (2017). doi:10.1007/ s00063-017-0302-0

24. Marik PE. Noninvasive cardiac output monitors: a state-of the-art review. J Cardiothorac Vasc Anesth (2013) 27(1):121-34. doi:10.1053/j. jvca.2012.03.022

25. Song R, Rich W, Kim JH, Finer NN, Katheria AC. The use of electrical cardiometry for continuous cardiac output monitoring in preterm neonates: a validation study. Am J Perinatol (2014) 31(12):1105-10. doi:10.1055/s-00341371707

26. Hsu KH, Wu TW, Wu IH, Lai MY, Hsu SY, Huang HW, et al. Electrical cardiometry to monitor cardiac output in preterm infants with patent ductus arteriosus: a comparison with echocardiography. Neonatology (2017) 112(3):231-7. doi:10.1159/000475774

27. Boet A, Jourdain G, Demontoux S, De Luca D. Stroke volume and cardiac output evaluation by electrical cardiometry: accuracy and reference nomograms in hemodynamically stable preterm neonates. J Perinatol (2016) 36(9):748-52. doi:10.1038/jp.2016.65

28. Piasek CZ, Van Bel F, Sola A. Perfusion index in newborn infants: a noninvasive tool for neonatal monitoring. Acta Paediatr (2014) 103(5):468-73. doi:10.1111/apa.12574

29. Takahashi S, Kakiuchi S, Nanba Y, Tsukamoto K, Nakamura T, Ito Y. The perfusion index derived from a pulse oximeter for predicting low superior vena cava flow in very low birth weight infants. J Perinatol (2010) 30(4):265-9. doi:10.1038/jp.2009.159

30. Alderliesten T, Lemmers PM, Baerts W, Groenendaal F, van Bel F. Perfusion index in preterm infants during the first 3 days of life: reference values and relation with clinical variables. Neonatology (2015) 107(4):258-65. doi:10.1159/ 000370192

31. Gomez-Pomar E, Makhoul M, Westgate PM, Ibonia KT, Patwardhan A, Giannone PJ, et al. Relationship between perfusion index and patent ductus arteriosus in preterm infants. Pediatr Res (2017) 81(5):775-9. doi:10.1038/ pr.2017.10

32. De Felice C, Latini G, Vacca P, Kopotic RJ. The pulse oximeter perfusion index as a predictor for high illness severity in neonates. Eur J Pediatr (2002) 161(10):561-2. doi:10.1007/s00431-002-1042-5

33. Tuten A, Dincer E, Topcuoglu S, Sancak S, Akar S, Hakyemez Toptan H, et al. Serum lactate levels and perfusion index: are these prognostic factors on mortality and morbidity in very low-birth weight infants? J Matern Fetal Neonatal Med (2017) 30(9):1092-5. doi:10.1080/14767058.2016.1205019

34. Van Laere D, O’Toole JM, Voeten M, McKiernan J, Boylan GB, Dempsey E. Decreased variability and low values of perfusion index on day one are associated with adverse outcome in extremely preterm infants. J Pediatr (2016) 178:119-24.e1. doi:10.1016/j.jpeds.2016.08.008
35. Dix LM, van Bel F, Lemmers PM. Monitoring cerebral oxygenation in neonates: an update. Front Pediatr (2017) 5:46. doi:10.3389/fped.2017.00046

36. Yoxall CW, Weindling AM, Dawani NH, Peart I. Measurement of cerebral venous oxyhemoglobin saturation in children by near-infrared spectroscopy and partial jugular venous occlusion. Pediatr Res (1995) 38(3):319-23. doi:10.1203/00006450-199509000-00008

37. Alderliesten T, Dix L, Baerts W, Caicedo A, van Huffel S, Naulaers G, et al. Reference values of regional cerebral oxygen saturation during the first 3 days of life in preterm neonates. Pediatr Res (2016) 79(1-1):55-64. doi:10.1038/ pr.2015.186

38. Dix LM, van Bel F, Baerts W, Lemmers PM. Comparing near-infrared spectroscopy devices and their sensors for monitoring regional cerebral oxygen saturation in the neonate. Pediatr Res (2013) 74(5):557-63. doi:10.1038/pr.2013.133

39. Kenosi M, O’Toole JM, Hawkes GA, Hutch W, Low E, Wall M, et al. Monitoring cerebral oxygenation of preterm infants using a neonatal specific sensor. J Perinatol (2017). doi:10.1038/s41372-017-0007-5

40. Hyttel-Sorensen S, Pellicer A, Alderliesten T, Austin T, van Bel F, Benders M, et al. Cerebral near infrared spectroscopy oximetry in extremely preterm infants: phase II randomised clinical trial. BMJ (2015) 350:g7635. doi:10.1136/ bmj.g7635

41. Plomgaard AM, Alderliesten T, Austin T, van Bel F, Benders M, Claris O, et al. Early biomarkers of brain injury and cerebral hypo- and hyperoxia in the SafeBoosC II trial. PLoS One (2017) 12(3):e0173440. doi:10.1371/journal. pone. 0173440

42. O’Toole JM, Kenosi M, Finn D, Boylan GB, Dempsey EM. Features of cerebral oxygenation detects brain injury in premature infants. Conf Proc IEEE Eng Med Biol Soc (2016) 2016:3614-7. doi:10.1109/embc.2016.7591510

43. Mitra S, Czosnyka M, Smielewski P, O’Reilly H, Brady K, Austin T. Heart rate passivity of cerebral tissue oxygenation is associated with predictors of poor outcome in preterm infants. Acta Paediatr (2014) 103(9):e374-82. doi:10.1111/apa.12696

44. Kooi EMW, Verhagen EA, Elting JWJ, Czosnyka M, Austin T, Wong FY, et al. Measuring cerebrovascular autoregulation in preterm infants using near-infrared spectroscopy: an overview of the literature. Expert Rev Neurother (2017) 17(8):801-18. doi:10.1080/14737175.2017.1346472

45. Caicedo A, Varon C, Alderliesten T, Lemmers P, van Bel F, Naulaers G, et al. Differences in the cerebral hemodynamics regulation mechanisms of premature infants with intra-ventricular hemorrhage assessed by means of phase rectified signal averaging. Conf Proc IEEE Eng Med Biol Soc (2014) 2014:4208-11. doi:10.1109/embc.2014.6944552

46. da Costa CS, Czosnyka M, Smielewski P, Mitra S, Stevenson GN, Austin T. Monitoring of cerebrovascular reactivity for determination of optimal blood pressure in preterm infants. J Pediatr (2015) 167(1):86-91. doi:10.1016/j. jpeds.2015.03.041

47. Riera J, Cabanas F, Serrano JJ, Bravo MC, Lopez-Ortego P, Sanchez L, et al. New time-frequency method for cerebral autoregulation in newborns: predictive capacity for clinical outcomes. J Pediatr (2014) 165(5):897-902.e1. doi:10.1016/j.jpeds.2014.06.008

48. Stammwitz A, von Siebenthal K, Bucher HU, Wolf M. Can the assessment of spontaneous oscillations by near infrared spectrophotometry predict neurological outcome of preterm infants? Adv Exp Med Biol (2016) 876:521-31. doi:10.1007/978-1-4939-3023-4_65

49. Fairchild KD, Schelonka RL, Kaufman DA, Carlo WA, Kattwinkel J, Porcelli PJ, et al. Septicemia mortality reduction in neonates in a heart rate characteristics monitoring trial. Pediatr Res (2013) 74(5):570-5. doi:10.1038/pr.2013.136

50. Temko A, Sarkar AK, Boylan GB, Mathieson S, Marnane WP, Lightbody G. Toward a personalized real-time diagnosis in neonatal seizure detection. IEEE J Transl Eng Health Med (2017) 5:2800414. doi:10.1109/jtehm.2017.2737992

Conflict of Interest Statement: The authors declare that the research was conducted in the absence of any commercial or financial relationships that could be construed as a potential conflict of interest.

Copyright (c) 2018 Van Laere, Voeten, O’ Toole and Dempsey. This is an open-access article distributed under the terms of the Creative Commons Attribution License (CC BY). The use, distribution or reproduction in other forums is permitted, provided the original author(s) and the copyright owner are credited and that the original publication in this journal is cited, in accordance with accepted academic practice. No use, distribution or reproduction is permitted which does not comply with these terms. 